\title{
MULTIPLICAÇÃO in vitro DO PORTA-ENXERTO DE Prunus spp. 'CARELLI'1
}

\author{
PAULO DE TARSO TEIXEIRA², APARECIDO LIMA DA SILVA ${ }^{3}$ JEAN-PIERRE HENRI JOSEPH DUCROQUET ${ }^{4}$, \\ MIGUEL PEDRO GUERRA ${ }^{5}$
}

\begin{abstract}
RESUMO - No Brasil, a falta de porta-enxertos para as Prunáceas, principalmente de origem clonal, tem incentivado a seleção de novas variedades e o uso de técnicas de cultura in vitro para a propagação. Neste sentido, o objetivo deste trabalho foi avaliar o potencial de multiplicação in vitro do porta-enxerto 'Carelli' sob efeito de diferentes concentrações da citocinina 6-benzilaminopurina (BAP). Segmentos nodais com 0,5 cm de comprimento foram inoculados em meio de cultura de Lepoivre, suplementado com 0,0; 0,5; 1,0; 2,0 e 4,0 mg.L $\mathrm{L}^{-1}$ BAP. Estes segmentos nodais são oriundos de plântulas preestabelecidas in vitro, após duas subculturas em meio de cultura de Lepoivre, suplementado com $0,5 \mathrm{mg} . \mathrm{L}^{-1} \mathrm{de}$ BAP. As avaliações para número de brotos por explante e altura média das brotações foram realizadas após 21 dias de cultura in vitro. Os resultados mostraram que os tratamentos com BAP não apresentaram diferenças significativas entre si. A taxa média de multiplicação foi de 3,3 a 3,4 brotos por explante. $\mathrm{O}$ tratamento sem adição de BAP não apresentou a formação de brotações axilares, mas resultou em brotos com maior altura média (16,2 mm). O uso de BAP afetou significativamente a altura das brotações, e o acréscimo nas suas concentrações reduziu o comprimento das mesmas. Concentrações de BAP superiores a 1,0 mg.L $\mathrm{L}^{-1}$ de BAP reduziram o comprimento das brotações e promoveram hiperidricidade. O uso de $0,5 \mathrm{mg} . \mathrm{L}^{-1} \mathrm{de}$ BAP promoveu a formação de 3,3 brotos por explante com 11,0 mm de altura média, em condições adequadas para o enraizamento.
\end{abstract}

Termos de indexação: Pessegueiro; micropropagação; mudas

\section{In vitro MULTIPLICATION OF Prunus spp. ROOTSTOCKS 'CARELLI'}

ABSTRACT - In Brazil the lack of well adapted rootstocks in the Peach industry, mainly of clonal origin, forces the selection of new varieties and the use of tissue culture techniques for the mass clonal propagation. In the present work it was evaluated the in vitro multiplication potential of "Carelli" rootstock in response to different levels of BA. Nodal segments $(0.5 \mathrm{~cm}$ length) were inoculated in test tubes containing $20 \mathrm{ml}$ of Lepoivre culture medium supplemented with $0.0 ; 0.5 ; 1.0 ; 2.0$ and 4.0 mg.L.-1 BA. This nodal segments were originated from in vitro pre-established plants after two subcultures in Lepoivre culture medium supplemented with $0.5 \mathrm{mg} . \mathrm{L}^{-1} \mathrm{BA}$. Evaluations done after 21 days in culture showed that the different levels of BA resulted in values statistically similar for the multiplication rate and length of regenerated shoots. The values for multiplication rate ranged from 3.3 to 3.4 shoots/explant. The treatment control did not result in multiple shoots but showed shoots with the highest lengh (16.2 mm). BA significativelly affected the length of shoots and the increase in its levels reduced the shoot lengh. BA levels higher than $1.0 \mathrm{mg} . \mathrm{L}^{-1}$ reduced the shoot length and promoted vitrification. BA in the level of $0.5 \mathrm{mg} . \mathrm{L}^{-1}$ resulted in the induction of 3.3 shoots/explant with means values of $11.0 \mathrm{~mm}$ in length in adequate conditions for rooting.

Index terms: Peach; micropropagation; stocks

No Brasil, as mudas comerciais de Prunáceas, especialmente do pessegueiro, são obtidas através da enxertia sobre porta-enxertos originários de sementes de qualquer cultivar de maturação tardia, que apresente boa adaptação às condições edafoclimáticas da região. Essas sementes são oriundas da indústria de conserva, onde geralmente ocorrem misturas varietais, causando variabilidade genética e, conseqüentemente, a desuniformidade nos pomares (Fachinello, 2000).

O porta-enxerto mais utilizado na produção de mudas é o 'Capdeboscq' (Prunus persica (L.) Batsch), cultivar de ciclo tardio, cultivada para fins industriais, cujas sementes apresentam boas taxas de germinação. Essa cultivar é originária da Estação Experimental de Pelotas, obtida por polinização livre de um cruzamento entre 'Lake City' e uma seleção local chamada 'Intermediário’ (Finardi, 1998).

A necessidade de novas variedades de porta-enxertos encontra-se associada a métodos mais eficientes de propagação e produção de mudas (Fachinello, 2000). Assim, o porta-enxerto 'Carelli', originário de uma seleção da cultivar Capdeboscq, em Videira (SC), apresenta grande potencial para estudos de multiplicação in vitro e clonagem em larga escala, devido às suas características de induzir baixo vigor (ananizante) em ameixeira, o que pode permitir a implantação de pomares adensados, facilitando o manejo e aumentando a produtividade por área.

Para o gênero Prunus, tem se verificado grande progresso nas técnicas de cultura in vitro, com o uso de novos genótipos associado ao avanço técnico-científico nos métodos de propagação in vitro (Pérez-
Tornero et al., 2000; Silveira et al., 2001; Rogalski, 2002; Silva et al., 2003).

Entretanto, devido às diferenças genotípicas no comportamento in vitro, faz-se necessário determinar as condições ideais de multiplicação para cada genótipo. Neste contexto, os reguladores de crescimento são fundamentais para o sucesso da micropropagação e, dentre estes, as citocininas são indispensáveis para a quebra da dominância apical, indução e proliferação de gemas axilares (Leontiev-Orlov et al., 2000; Pérez-Tornero et al., 2000; Rogalski, 2002).

O BAP (6-benzilaminopurina) tem sido a citocinina mais eficaz na multiplicação in vitro em diversas espécies do gênero Prunus (Leontiev-Orlov et al., 2000; Rogalski, 2002; Rogalski et al.; 2003). Para a multiplicação do pessegueiro, o BAP atua na formação e no desenvolvimento de brotações in vitro com condições adequadas para a fase de enraizamento (Silveira et al., 2001; Rogalski, 2002; Silva et al., 2003; Channuntapipat et al., 2003).

Assim, o objetivo deste trabalho foi avaliar o potencial de multiplicação in vitro do porta-enxerto de Prunus 'Carelli' sob o efeito de diferentes concentrações de BAP.

O porta-enxerto 'Carelli' é uma seleção do 'Capdeboscq' selecionado pela Epagri. Plantas-matrizes desta variedade, originárias da Estação Experimental de Videira, são mantidas em sistema de fertirrigação em casa de vegetação para avaliação e experimentos no Departamento de Fitotecnia, Centro de Ciências Agrárias / Universidade Federal de Santa Catarina.

Das plantas-matrizes, foram coletados brotos em crescimento

\footnotetext{
${ }^{1}$ (Trabalho 030/2004). Recebido: 19/04/2004. Aceito para publicação: 21/07/2004.

${ }^{2}$ Eng $^{\mathrm{o}}$. Agr ${ }^{\circ}$. Mestrando do Programa de Pos-Graduação em Recursos Geneticos Vegetais, Universidade Federal de Santa Catarina, C.P. 476, 88040-900, Florianópolis, SC, (48) 331-5330, E-mail: plima37@yahoo.com.br.

${ }_{3}^{3}$ Prof. Adjunto da Universidade Federal de Santa Catarina, Departamento de Fitotecnia, C.P. 476, 88040-900, Florianópolis, SC, (48) 331-5330, E-mail: alsilva@ cca.ufsc.br. ${ }^{4}$ Eng $^{\circ}$. Agr ${ }^{\circ}$ Doutor, Empresa de Pesquisa e Extensão Rural de Santa Catarina, Estação Experimental de São Joaquim, C.P. 81, CEP: 88.600-000, São Joaquim, SC, (49) 233-0324, E-mail: ducroquet@epagri.rct-sc.br.

${ }_{5}^{5}$ Prof. Titular da Universidade Federal de Santa Catarina, Departamento de Fitotecnia, C.P. 476, 88040-900, Florianópolis, SC, (48) 331-5330, E-mail: mpguerra@cca.ufsc.br.
} 
ativo, que foram seccionados em segmentos com três a quatro gemas axilares e posteriormente submetidos ao seguinte processo de desinfestação: lavagem em água e detergente ( 10 gotas. $\mathrm{L}^{-1}$ de Tween 20$)$ e, posteriormente, sob agitação, por 1 minuto em etanol 70\%, 15 minutos em hipoclorito de sódio $(1,25 \%)$. Após a assepsia, em câmara de fluxo laminar, os explantes foram lavados com água destilada autoclavada (3 $\mathrm{x})$.

As gemas laterais foram introduzidas em tubos de ensaio (25x150 mm) contendo $20 \mathrm{~mL}$ de meio de cultura composto de sais e vitaminas de Lepoivre (Quoirin et al., 1977), suplementado com sacarose (20 g.L $\left.\mathrm{L}^{-1}\right)$, ágar $\left(7 \mathrm{~g} . \mathrm{L}^{-1}\right)$ e 6-benzilaminopurina $\left(0,5 \mathrm{mg} . \mathrm{L}^{-1}\right)$.

Segmentos nodais $(0,5 \mathrm{~cm})$ oriundos da fase de estabelecimento in vitro foram inoculados em meio de cultura Lepoivre (Quoirin et al., 1977) suplementado com BAP $\left(0,0 ; 0,5 ; 1,0 ; 2,0\right.$ e 4,0 mg.L $\left.\mathrm{L}^{-1}\right)$. O pH do meio de cultura foi ajustado para 5,2-5,3 e todos os componentes do meio foram adicionados antes da autoclavagem $\left(121^{\circ} \mathrm{C}, 20\right.$ minutos $) . \mathrm{O}$ material vegetal foi mantido em câmara de crescimento com temperatura de $25 \pm 2^{\circ} \mathrm{C}$, fotoperíodo de 16 horas de luz $\left(40-45 \mu \mathrm{mol} \cdot \mathrm{m}^{-2} \cdot \mathrm{s}^{-1}\right)$.

Após 21 dias, avaliaram-se o número de brotos por explante e a altura média das brotações. A variável altura de brotos foi determinada com auxílio de paquímetro, avaliando-se todas as brotações por explante para cada tratamento e repetição. O delineamento experimental utilizado foi inteiramente ao acaso, com cinco tratamentos e cinco repetições, sendo cada repetição constituída de um frasco com cinco explantes. Os dados obtidos, não transformados, foram submetidos à Análise de Variância (ANOVA) e ao teste de separação de médias SNK (5\%), de acordo com Sokal \& Rohlf (1995).

Os resultados para número de brotos por explante são apresentados na Tabela 1. A análise dos dados permite identificar dois grupos distintos. O primeiro foi composto pelo tratamento-testemunha, sem presença de BAP, onde não ocorreu a formação de brotações múltiplas. O segundo grupo foi composto pelos tratamentos com BAP, com o desenvolvimento de brotações múltiplas. Não foi possível detectar diferenças significativas entre as concentrações testadas.

TABELA 1 - Efeito do regulador vegetal BAP no número e altura das brotações desenvolvidas para o porta-enxerto de Prunus 'Carelli'. UFSC/CCA/LMBV, Florianópolis, 2003.

\begin{tabular}{ccc}
\hline $\begin{array}{c}\text { Concentrações de } \\
\text { BAP }\left(\mathbf{m g . L ^ { - 1 }}\right)\end{array}$ & $\begin{array}{c}\text { Número de brotos } \\
\text { por explante* }\end{array}$ & $\begin{array}{c}\text { Altura média dos } \\
\text { brotos* }(\mathbf{m m})\end{array}$ \\
\hline 0,0 & $1,0 \mathrm{a}$ & $16,2 \mathrm{a}$ \\
0,5 & $3,3 \mathrm{~b}$ & $11,0 \mathrm{~b}$ \\
1,0 & $3,4 \mathrm{~b}$ & $10,8 \mathrm{~b}$ \\
2,0 & $3,3 \mathrm{~b}$ & $7,5 \mathrm{~b}$ \\
4,0 & $3,4 \mathrm{~b}$ & $6,6 \mathrm{~b}$ \\
F & 13,7 & 5,8 \\
\hline C.V. $(\%)$ & 22,1 & 33,5 \\
\hline
\end{tabular}

*Médias seguidas pela mesma letra não diferem entre si, pelo teste $\operatorname{SNK}(0,05)$

Os resultados demonstram que, para o porta-enxerto 'Carelli', é necessário o uso da citocinina BAP para a proliferação de gemas axilares. As concentrações de BAP usadas $\left(0,5\right.$ a $\left.4,0 \mathrm{mg} . \mathrm{L}^{-1}\right)$ demonstraram um comportamento semelhante em termos de multiplicação in vitro, com taxa de 3,3 a 3,4 brotos por explante. Estes valores são similares aos observados por Silveira et al. (2001), para cinco porta-enxertos de Prunus, em concentrações de 0,5 e $0,7 \mathrm{mg} . \mathrm{L}^{-1} \mathrm{BAP}$. No entanto, para três portaenxertos de Prunus, Silva et al. (2003) obtiveram taxas mais elevadas de multiplicação in vitro, com valores variando de 10,5 a 16,0 brotações, indicando que o número de brotos é dependente do genótipo. Channuntapipat et al. (2003), trabalhando com um porta-enxerto híbrido de Prunus, obtiveram elevado número médio de brotos por explante $(36,0)$ com a concentração de $5 \mu \mathrm{M}\left(1,125 \mathrm{mg} . \mathrm{L}^{-1}\right)$ de BAP. Trabalhando com o pessegueiro 'Capdeboscq', Rogalski (2002) obteve o maior número de brotos $(25,9)$ em resposta à concentração de BAP a $1,5 \mathrm{mg} . \mathrm{L}^{-1}$. Rogalski et al. (2003), trabalhando com ameixeira Santa Rosa, também não encontraram diferenças significativas para a variável número de brotos por explante, testando diferentes concentrações de BAP. Entretanto, o maior número de brotos por explante $(3,6)$ encontrado foi obtido em resposta à concentração de $2,0 \mathrm{mg} \cdot \mathrm{L}^{-1}$.

Observou-se que a maior altura média de brotos $(16,2 \mathrm{~mm})$ foi obtida no tratamento-testemunha (ausência de BAP), que diferiu estatisticamente dos demais tratamentos (Tabela 1). Embora sem diferença entre os tratamentos, as menores concentrações $\left(0,5\right.$ e $\left.1,0 \mathrm{mg} . \mathrm{L}^{-1}\right)$ resultaram em valores médios superiores para a altura dos brotos, com 11,0 e 10,8 mm, respectivamente. Estes resultados são similares aos observados para o pessegueiro (Rogalski, 2002; Silva et al., 2003) e ameixeira (Leontiev-Orlov et al., 2000; Rogalski et al., 2003).

Neste trabalho, observou-se um decréscimo na altura dos brotos com o aumento das concentrações de BAP. Para Leontiev-Orlov et al. (2000) e Rogalski et al. (2003), em ameixeira, a altura média dos brotos in vitro foi afetada pela concentração de BAP, reduzindo-se com o aumento da concentração desta citocinina. Para estes autores, concentrações superiores a $0,5 \mathrm{mg} . \mathrm{L}^{-1}$ de BAP inibiram o alongamento das brotações. Channuntapipat et al. (2003), trabalhando com um porta-enxerto híbrido de pessegueiro, observaram os maiores valores para tamanho de brotos com a concentração de $10 \mu \mathrm{M}$ de $\operatorname{BAP}\left(2,25 \mathrm{mg} \cdot \mathrm{L}^{-1}\right)$.

A citocinina BAP tem sido freqüentemente empregada na multiplicação in vitro de porta-enxerto de Prunus (Silveira et al., 2001; Silva et al., 2003; Channuntapipat et al., 2003). Entretanto, alta concentração desse regulador de crescimento pode induzir a redução de alongamento de brotos e hiperidricidade, em prunáceas (Leontiev-Orlov et al., 2000; Rogalski 2002; Rogalski et al., 2003).

Neste trabalho, verificou-se que as concentrações de 2,0 e 4,0 mg.L $\mathrm{L}^{-1}$ de BAP promoveram hiperidricidade dos explantes. Esse é um desequilíbrio fisiológico que pode estar relacionado a diferentes causas, entre as quais, ao efeito de altas concentrações de citocininas (Debergh et al., 1992; Pérez-Tornero et al., 2000; Rogalski, 2002).

Em conclusão, a metodologia empregada no presente trabalho para a multiplicação in vitro do porta-enxerto de Prunus 'Carelli' foi eficaz, com resultados promissores para propagação em larga escala. $\mathrm{O}$ uso de BAP na concentração de $0,5 \mathrm{mg} . \mathrm{L}^{-1}$ possibilitou regenerar 3,3 brotos/explante com condições adequadas para enraizamento. As concentrações maiores que $1,0 \mathrm{mg} . \mathrm{L}^{-1}$ de BAP inibiram o alongamento das brotações e promoveram a hiperidricidade.

\section{REFERÊNCIAS BIBLIOGRÁFICAS}

CHANNUNTAPIPAT, C.; SEDGLEY, M.; COLLINS, G. Micropropagation of almond cultivars Nonpareil and Ne Plus Ultra and the hybrid rootstock Titan X Nemaguard. Scientia Horticulturae, Amsterdam, v.98, n.4, p.473-484, 2003.

DEBERGH, P.; AITKEN-CHRISTIE, J.; COHEN, D.; GROUT, B.; VONARNOLD, S.; ZIMMERMAN, R.; ZIV, M. Reconsideration of the term 'vitrification' as used in micropropagation. Plant Cell, Tissue and Organ Culture, Dordrecht, v.30, p.135-140, 1992.

FACHINELLO, J.C. Problemática das mudas de plantas frutíferas de caroço. In: SIMPÓSIO INTERNACIONAL DE FRUTAS DE CAROÇO: PÊSSEGOS, NECTARINAS EAMEIXAS, 1., 2000, Porto Alegre. Anais... p.25-40.

FINARDI, N.L. Métodos de propagação e descrição de porta-enxertos, In: MEDEIROS, C.A B.; RASEIRA, M.C.B. A cultura do pessegueiro. Pelotas: Embrapa-CPACT, 1998. p. 100-129.

LEONTIEV-ORLOV, O.; ROGALSKI, M.; MOSSI, A. J.; CANSIAN, R.L. 6-Benzilaminopurina (BAP) na multiplicação in vitro de prunáceas (Prunus sp). Revista Brasileira de Agrociência, Pelotas, v.6,p. 63$67,2000$.

PÉREZ-TORNERO, O.; LÓPEZ, J.M.; EGEA, J.; BURGOS, L. Effect of basal media and growth regulators on the in vitro propagation of apricot (Prunus armenica L.) cv. Canino. Journal of Horticultural Science \& Biotechnology, Ashford, v. 75, n.3, p.283-286, 2000.

QUOIRIN, M.; LEPOIVRE, P.; BOXUS, P. Un premier bilan de 10 années 
de recherches sur les cultures de méristèmes et la multiplication in vitro de fruitiers ligneux. Comptes Rendus des Recherches Agronomiques, Gembloux, p.93-117, 1977.

ROGALSKI, M. Propagação in vitro de porta-enxertos de Prunus: cultura de embriões, estabelecimento, multiplicação, enraizamento e aclimatização, 2002. 92f. Dissertação (Mestrado em Recursos Genéticos Vegetais) - Centro de Ciências Agrárias, Universidade Federal de Santa Catarina, Florianópolis, 2002.

ROGALSKI, M.; GUERRA, M. P.; SILVA, A. L. Multiplicação in vitro da ameixeira 'Santa Rosa': Efeito da Citocinina BAP. Revista Brasileira de Fruticultura, Jaboticabal, v. 25, n. 2, p.365-367, 2003.
SILVA, A.L.; ROGALSKI, M.; MORAES, L. K. A.; FESLIBINO, C.; CRESTANI L.; GUERRA, M. P. Estabelecimento e multiplicação in vitro de porta-enxertos de Prunus. Revista Brasileira de Fruticultura, Jaboticabal, v. 25, n.2, p.297-300, 2003.

SILVEIRA, A.C.P.; FACHINELO, J.C.; FORTES, G.R. de L.; CITADIN, I.; RODRIGUES, AC.; QUEZADA, A C.; SILVA, J.B. Multiplicação in vitro de porta-enxertos do gênero Prunus sob diferentes concentrações de BAP em dois meios de cultura, Revista Brasileira de Fruticultura, Jaboticabal, v.23, n. 3, p.488-492, 2001.

SOKAL, R.R.; ROHLF, F.J. Biometry. New York: W.H. Freeman and Company, 1995. 776p. 